Major Article

\title{
Evaluation of the immunogenicity of Schistosoma mansoni egg surface
}

\author{
Renata Russo Frasca Candido ${ }^{[1]}$, Timothy Guy St. Pierre ${ }^{[1]}$, Malcolm Kenneth Jones ${ }^{[2]}$ \\ and Carlos Graeff-Teixeira ${ }^{[3],[4]}$
}

\begin{abstract}
[1]. School of Physics, The University of Western Australia, Crawley, WA, Australia. [2]. School of Veterinary Sciences, The University of Queensland, Brisbane, QLD, Australia. [3]. Laboratório de Biologia Parasitária, Faculdade de Biociências, Pontifícia Universidade Católica do Rio Grande do Sul, Porto Alegre, RS, Brasil. [4]. Laboratório de Parasitologia Molecular,

Instituto de Pesquisas Biomédicas, Pontifícia Universidade Católica do Rio Grande do Sul, Porto Alegre, RS, Brasil.
\end{abstract}

\begin{abstract}
Introduction: Immunogenicity of Schistosoma mansoni egg surface was examined to determine whether intact eggshells have lower antigenicity than ruptured eggs. Methods: Swiss Webster mice were inoculated with intact or ultrasonicated S. mansoni eggs isolated from infected human feces. Mice were separated into four groups of six animals each and immunizations were performed approximately every 20 days during a 60-day period. Groups 1-4 were administered with saline solution, sonicated eggs with Freund's adjuvant, sonicated eggs without Freund's adjuvant, and intact eggs, respectively. IgG humoral immune response was assessed by ELISA using Soluble Egg Antigen produced from eggs isolated from the livers of infected mice. Results: Sonicated eggs co-administered with adjuvant induced the highest humoral response at 58 days, which was 11.9fold (95\% CI 6.2-17.5) greater than the response induced by saline solution. Sonicated eggs without adjuvant induced a 4.3fold stronger response (95\% CI 2.4-6.2) than normal saline. Intact eggs induced humoral response that was nominally twice stronger (95\% CI 0.8-3.2) than that induced by normal saline but the effect did not reach statistical significance. Conclusions: Soluble antigens are not abundant on the surface of S. mansoni eggs and/or are not secreted in sufficient quantities to induce a significant immune response to intact eggs. Assuming that isolation procedures had not damaged the eggs used for inoculation, our observations suggest that intact eggs either do not induce a significant immune response or, if they do, the mechanism involves insoluble antigens from the egg surface.
\end{abstract}

Keywords: Schistosomiasis. Egg antigens. Immune response.

\section{INTRODUCTION}

Schistosomiasis is an endemic chronic infection that occurs in Africa, South America, Caribbean islands, and Eastern Mediterranean $^{1,2}$. It remains one of the most prevalent parasitic infections and has significant economic and public health consequences $^{3}$. It is estimated that more than 250 million people in 78 countries are currently infected ${ }^{4}$.

The main causes of morbidity in chronic schistosomiasis are the parasite's eggs and immune responses that they evoke. Schistosoma mansoni worm pairs lay around 350 eggs per day. Experiments in mice have indicated that approximately onethird of the eggs successfully migrate to the gut lumen and are evacuated with feces. The remaining eggs become trapped in host tissues and organs, especially the liver ${ }^{6}$. Liver-entrapped

Corresponding author: Dra. Renata Russo Frasca Candido.

e-mail: renatarusso.candido@gmail.com

Received 20 April 2017

Accepted 26 September 2017 eggs mature and die, inducing a potent granulomatous immune response in the host ${ }^{7,8}$. Once the parasites are eliminated, the granulomatous pathology, the extent of fibrosis, and immune cell infiltrates in the liver are greatly reduced ${ }^{9}$.

Elevated immunoglobulin E levels as well as blood and tissue eosinophilia are the hallmarks of the immune response to schistosomiasis ${ }^{10}$. Increased serum IgE levels have been demonstrated in humans and rats infected with Schistosoma $a^{11,12}$. One key observation regarding the modulation of the host response to $S$. mansoni infection is the polarization of helper 1 (Th1) or helper 2 (Th2) responses of cluster of differentiation $4+(\mathrm{CD} 4+) \mathrm{T}$ lymphocytes. These responses are distinguished according to the pattern of cytokines produced by respective cells. Th1 lymphocytes secrete interferon- $\gamma$, interleukin- 2 (IL-2), and tumor necrosis factor- $\beta$. These cytokines participate in the activation of macrophages and in delayed hypersensitivity reactions. In turn, Th2 lymphocytes produce IL-4, IL-5, IL-6, IL-9, IL-10, and IL-13, supporting the humoral immune response by stimulating the proliferation of B lymphocytes, production of immunoglobulin E (IgE) and immunoglobulin $\mathrm{G}(\operatorname{IgG})$, and differentiation of eosinophils and mast cells ${ }^{13-16}$. 
Previous studies have demonstrated that humoral and cellular immune responses are the key processes determining the development of schistosomiasis pathology. Between 3 to 5 weeks post-infection, the immunological response triggered against worm antigens is characterized by an increase in Th1 cytokines $^{17,18}$. From 6 to 8 weeks, simultaneously with egg deposition, the Th1 response is replaced by the Th2 response against the egg antigens ${ }^{16,18-20}$. Because different cytokines are secreted during Th1 and Th2 phases, the humoral response shows a characteristic pattern of antibody isotypes. The responses mediated by Th1 cells are associated with $\operatorname{IgG} 2 \mathrm{a},-\operatorname{IgG} 2 \mathrm{~b}$, and IgG3 antibodies, whereas the responses mediated by Th2 cells are associated with IgG1 and IgE isotypes. As has been demonstrated by Butterworth et al..$^{21}$, during early infections of young children, the major antigenic stimulus is the egg. Antigens released from eggs, including polysaccharides, elicit IgM or IgG antibodies that fail to mediate cell-dependent damage and cross-react with carbohydrate epitopes on the surface of the schistosomula.

The idea for the present study came from the results of the experiments during the development of the diagnostic method Helminte ${ }^{22}$. That method is based on the interaction of Schistosoma eggs with paramagnetic particles that bind to the parasite's egg surface ${ }^{23,24}$, thus enabling them to be magnetically isolated from fecal sediments. Several attempts involving various doses of immunizing and adjuvant agents demonstrated that it was problematic to obtain consistently high levels of antibodies against the surface of the egg. The objectives of this work were therefore to assess the immunogenicity of the surface of S. mansoni eggs by comparing the levels of $\mathrm{IgG}$ antibodies produced in different groups of mice immunized with intact or ultrasonicated eggs and to monitor the production of antibodies against $S$. mansoni eggs.

\section{METHODS}

\section{Maintenance of Schistosoma mansoni in laboratory conditions}

This study was designed and conducted in the Laboratory of Parasite Biology and the Molecular Parasitology Laboratory at the Biomedical Research Institute of the Pontifical Catholic University of Rio Grande do Sul (PUCRS). Schistosoma mansoni cercariae used in this study were isolated from the snails (Biomphalaria sp.) collected in Esteio, a municipality in Rio Grande do Sul in the south of Brazil. Swiss Webster mice experimentally infected with the cercariae were perfused after 50 days for the collection of adult worms.

\section{Acquisition of Schistosoma mansoni eggs}

Eggs from S. mansoni were isolated from the livers of experimentally infected mice ${ }^{25}$ for the production of the soluble egg antigen (SEA) and from a 300g sample of human stool obtained through collaboration with the Regional Management of the Control Program of Schistosomiasis in Minas Gerais, Brazil for the immunization of the mice used in this study.

\section{Isolation of eggs from fecal matter}

To isolate eggs from human stool, feces were dissolved in cooled saline $(0.9 \% \mathrm{NaCl}$ solution $)$ with $\mathrm{pH} 6.2$. The fecal matter was then filtered using a nylon sieve with a $500 \mu \mathrm{m}$ aperture into a conical sedimentation glass, with further serial washes until the supernatant was clean. The sediment was examined using optical microscopy and the eggs were separated and transferred one by one into VectaSpin Whatman microtubes (Sigma-Aldrich, St. Louis, MO, USA).

\section{Soluble egg antigen production}

SEA production was achieved according to the method described by Boros and Warren $(1970)^{26}$, modified as follows: the eggs were suspended in ice-cold saline solution and sonicated by using 152 min cycles at 30\% amplitude (Vibracell, Sonics \& Materials, Newtown, CT, USA). Phosphate buffered saline (PBS, 10×, pH 7.4) was added to the material and centrifuged at $30,000 \times g$ for $2 \mathrm{~h}$ at $4^{\circ} \mathrm{C}$. Protein concentration was measured using the Bradford method (Bio-Rad Laboratories, Hercules, $\mathrm{CA}$, USA), and the material was kept at $-20^{\circ} \mathrm{C}$ until use.

\section{Preparation of egg loads}

Isolated eggs were separated into individual microtubes as follows: 36 microtubes containing 500 eggs for immunizations at day 0 and day 20, and 18 microtubes containing 1,000 eggs for the immunizations at day 38 . The eggs used to immunize the mice were centrifuged twice at $440 \times g$ for 3 min each time in $0.25 \%$ sodium hypochlorite followed by three centrifugations at $440 \times \mathrm{g}$ for $3 \mathrm{~min}$ in saline. This procedure was necessary in order to prevent secondary bacterial infections and premature death of the immunized mice due to potential contaminants from feces.

\section{Immunization schedule and experimental groups}

A total of four groups each containing six mice were used for this study. Group 1 mice (control) received only saline throughout the study. Groups 2 and 3 mice were immunized with sonicated eggs. However, group 2 animals received both an emulsion of eggs and complete Freund's adjuvant (Gibco, Gaithersburg, MD, USA) during the first immunization, whereas during the remaining immunizations, they received incomplete Freund's adjuvant (Gibco, Gaithersburg, MD, USA). Finally, group 4 mice were immunized with intact eggs during the whole experiment. The eggs used in Groups 2 and 3 went through four cycles of 2 min sonication at an amplitude of $30 \%$ on ice. The inoculation schedule comprised a batch load of 500 eggs per mouse at days 0 and 20, and at day 38, each mouse received a load of 1,000 eggs injected subcutaneously at the back of the neck. Serum samples were obtained by peripheral venipuncture at $0,20,38$, and 58 days (Figure 1).

\section{Enzyme-linked immunosorbent assay}

For Enzyme-linked immunosorbent assay (ELISA) measurements, polystyrene plates containing 96 wells were used (Nunc F16 Polysorp, Sigma-Aldrich, St. Louis, MO, USA). Each measurement was repeated six times. The plates were sensitized with SEA diluted to $5 \mu \mathrm{g} / \mathrm{mL}$ in carbonate-coating buffer with $\mathrm{pH}$ adjusted to 9.6. The plates were incubated for $2 \mathrm{~h}$ at $24^{\circ} \mathrm{C}$ followed by $24 \mathrm{~h}$ overnight in the refrigerator, according to the standard procedure used in the laboratory. Each plate 


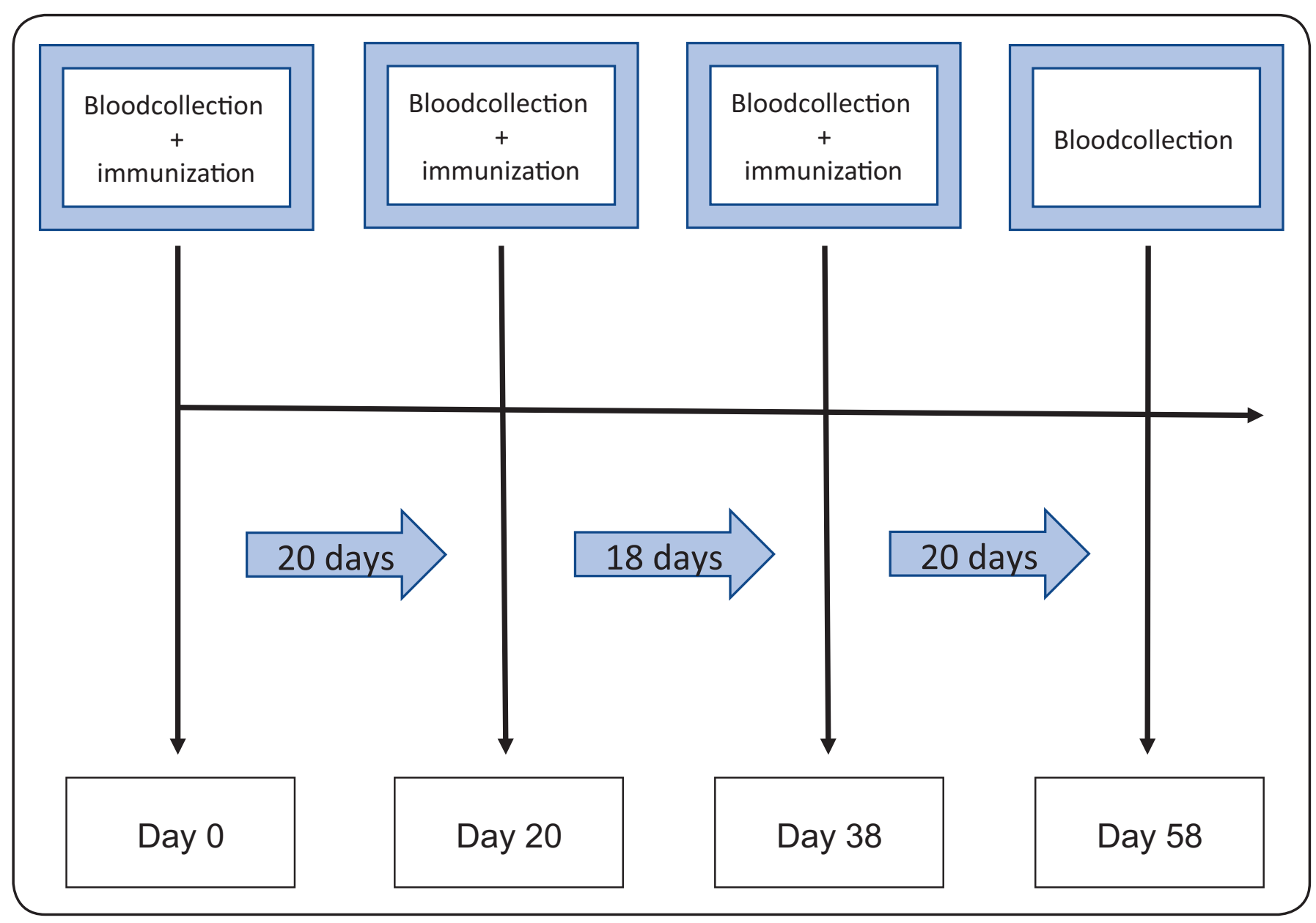

FIGURE 1 - Immunization schedule.

was washed three times with phosphate buffered saline (PBS) containing 0.05\% Tween-20 at pH 7.2 (PBS-T) and blocked with 5\% skimmed milk in PBS for $3 \mathrm{~h}$ at room temperature to avoid cross-reactivity. The plates were washed three times with PBS-T. The primary antibodies were diluted $1: 100$ in 5\% skimmed milk in PBS and added to each well in duplicate. After incubation for another $2 \mathrm{~h}$ at $24^{\circ} \mathrm{C}$ and repeated washes, the secondary horseradish peroxidase-conjugated goat anti-mouse IgG antibody (Invitrogen, Carlsbad, CA, USA) was added for $2 \mathrm{~h}$ at $24^{\circ} \mathrm{C}$. Following another set of washes, o-phenylenediamine with $3 \% \mathrm{H}_{2} \mathrm{O}_{2}$ in $0.02 \mathrm{M}$ citric acid was used to develop the peroxidase reaction, and the plates were incubated for $15 \mathrm{~min}$ in the dark at $24^{\circ} \mathrm{C}$. The reaction was finalized by the addition of $0.2 \mathrm{~N} \mathrm{HCl}$. Optical density was measured with a microtiter plate spectrophotometer (Anthos, Zenyth 340 r, Salzburg, Austria) using a 450nm filter.

\section{Statistical analysis}

One-way analysis of variance (ANOVA) was used to assess the differences in mean humoral responses in serum samples from each group of mice 58 days after first immunization. Post hoc Tukey's multiple comparison test was then used to determine the significance of differences in mean humoral response between each pair of immunization treatments.

\section{Ethical considerations}

During this study, 24 Swiss Webster mice were used. The animals were kept in a cage system (Tecniplast S. p. A., Buguggiate, VA, Italy) with individual isolation, filtered air, and controlled temperature. Before the immunizations and during each blood collection, the animals were anesthetized with inhaled isoflurane. This work was approved by the Ethics Committee in Research of the PUCRS (Protocol 07/03599).

\section{RESULTS}

One-way ANOVA indicated that there were significant $(P<0.0001)$ differences between mean humoral responses in the serum samples of mice that underwent different types of immunization after 58 days. Sonicated eggs co-administered with adjuvant induced the highest humoral response at 58 days, as the response was 11.9 -fold [95\% confidence interval $195 \%$ CI) 6.2-17.5] greater than the response induced by normal saline (Figure 2). Sonicated eggs without adjuvant induced a 4.3-fold stronger response (95\% CI 2.4-6.2) than normal saline, whereas 


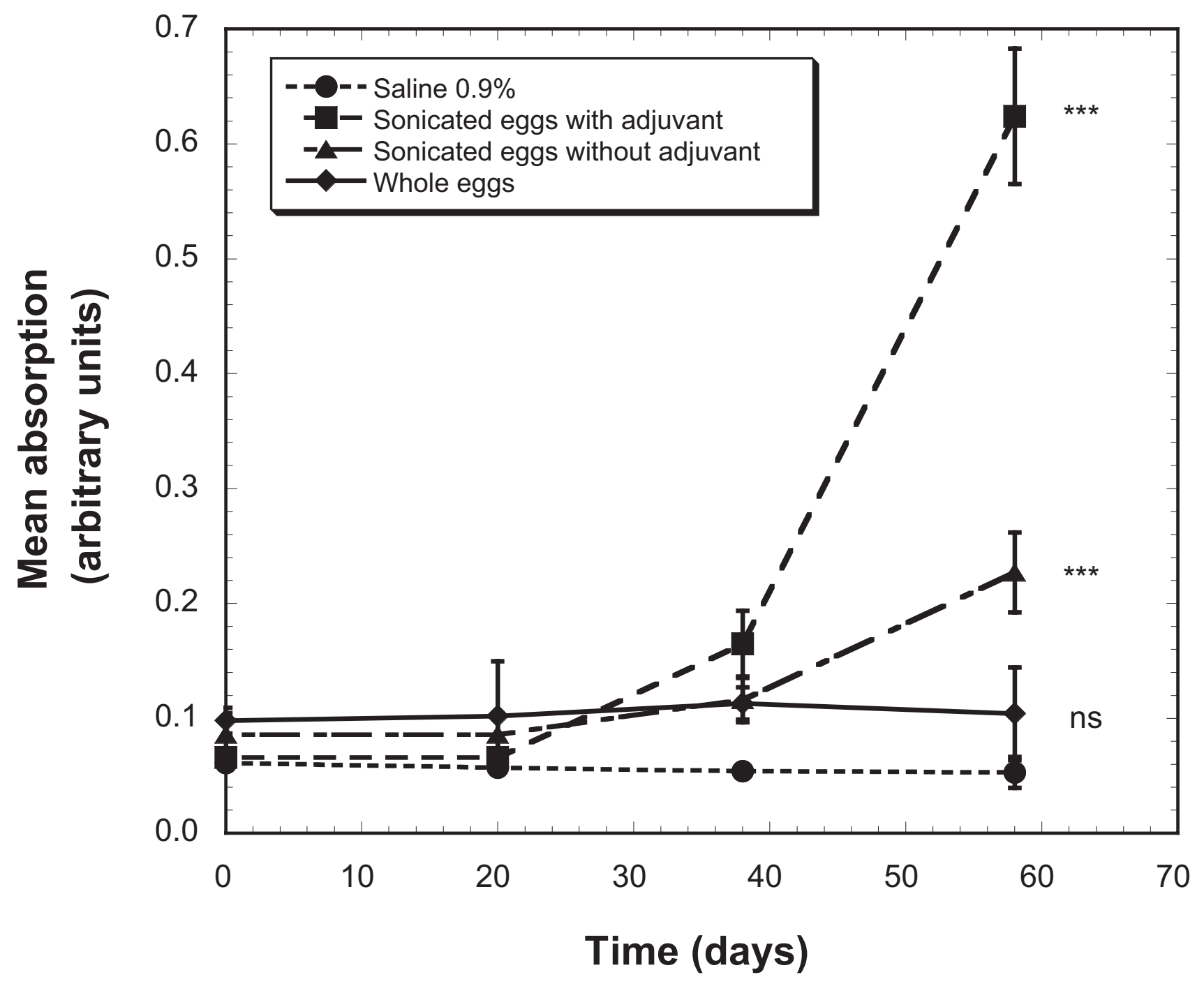

FIGURE 2 - Time course of mean humoral response in mice inoculated with intact eggs, sonicated eggs with adjuvant, sonicated eggs without adjuvant, or control saline solution. Data are presented as the mean \pm standard deviation; ns: not significantly different from control saline group at 58 days; *** — significantly different from control saline group at 58 days with $P<0.001$ (one-way analysis of variance followed by the post hoc Tukey's test).

intact eggs induced humoral response that was numerically twice greater than that to saline (95\% CI 0.8-3.2), but the effect did not reach statistical significance (Figure 2). Post hoc Tukey's multiple comparison test showed that there were significant $(P<0.001)$ differences in the effect on mean humoral responses at 58 days between all pairs of treatments, except between immunization with whole intact eggs and administration of saline (Figure 2).

\section{DISCUSSION}

In the present study, we measured IgG humoral immune response to soluble egg antigen of $S$. mansoni and demonstrated that intact eggshells have lower antigenicity than eggs ruptured by sonication.

Available evidence suggests that egg passage through the tissues is dependent on host immune response both in rodents ${ }^{27}$ and in humans ${ }^{28}$. It is believed that the migration through the tissues is facilitated by soluble secretions excreted by the eggs through the micropores present in egg shells ${ }^{23,29-33}$. Schistosoma mansoni egg proteome has been characterized in many studies, because the pathogenic consequences of the interaction of egg molecules with host immune system as well as the processes that underlie egg passage through the tissues and subsequent release with the feces are still poorly understood. It is still not known where inside the egg or when during its development a particular protein is expressed ${ }^{34}$. It is believed that the mechanisms by which the eggs travel through the intestinal wall tissues include modulation of local immune responses favoring their migration towards the intestinal lumen. Furthermore, the intestinal mucosa is an environment with a certain degree of antigen tolerance ${ }^{35,36}$, which likely adds to the reduced antigenicity of intact egg surface. 
Nevertheless, the results of our current study are consistent with previous observations, in which eggshells were found to be less immunogenic ${ }^{37}$, whereas inner elements of the egg were demonstrated to have a high antigenic potential ${ }^{38-40}$. In 1986, Linden $^{37}$ concluded that direct immunological detection of the eggs is only possible when the eggs rupture and the antigens become exposed, because the eggs are wrapped by a poorly antigenic eggshell. Our study showed that 58 days after the initial immunization, a small and insignificant difference was found between the immune response of mice to whole eggs and their response to saline, whereas much larger and statistically significant differences were found between their immune responses to sonicated eggs and the response to saline. These results suggest that soluble antigens are not abundant on the surface of S. mansoni eggs and/or are not secreted in sufficient quantities to induce a significant immune response to intact eggs. This means that intact eggs either do not induce a significant immune response or, if they do, the mechanism involves insoluble antigens on egg surface. However, care should be taken in extending these results (obtained from the eggs found in feces) to the properties of eggs at an earlier stage of the cycle. There is a possibility that eggs found in feces may not produce antigens at the same rate as eggs at an earlier stage in the cycle.

One interesting mechanism of escaping from host reactions is the attachment of Schistosoma eggs to the vascular endothelium. It is known that Schistosoma eggshells bind platelets ${ }^{41}$, plasma proteins, von Willebrand factor, fibrinogen, and fibronectin ${ }^{42}$. Furthermore, File ${ }^{43}$ demonstrated that the endothelium rapidly grows over the egg, entrapping it within tissues. Inside the host, the eggs move inside the vessels and cross venous walls and intestinal tissues. It is only when the eggs are entrapped and die, and not while they are moving and alive, that the immune system will recruit its cells, eventually resulting in granuloma formation ${ }^{44}$.

In conclusion, the difficulties of obtaining antibodies against intact egg shells observed previously in the development of the Helmintex method have been confirmed by our study, because significant immune response to $S$. mansoni eggs in mice was obtained only if the eggs were pretreated by sonication prior to inoculation. Our results provide insight into how the immunogenicity of schistosome eggs may change at different stages of the interaction with the host and during the passage through the tissues towards the external environment. Future investigations should explore other variables of humoral response, in particular the production of IgM and IgG antibodies, as well as examine alternative adjuvant schemes.

\section{Acknowledgments}

The authors would like to thank Tiago Giuliani from the Pathological Anatomy Laboratory and Daniel Marinowic from the Molecular and Cellular Laboratory of the Saint-Lucas Hospital of the Pontifical Catholic University of Rio Grande do Sul for the help with the experiments.

\section{Financial support}

Financial support was provided by Conselho Nacional de Desenvolvimento Científico e Tecnológico (CNPq) and Coordenação de Aperfeiçoamento de Pessoal de Nivel Superior (CAPES).

\section{Conflict of interests}

The authors declare that there is no conflict of interests.

\section{REFERENCES}

1. Caldas IR, Campi-Azevedo AC, Oliveira LFA, Silveira MAS, Oliveira RC, Gazzinelli G. Human schistosomiasis mansoni: Immune responses during acute and chronic phases of the infection. ActaTrop. 2008;108(2):109-17.

2. Gonçalves MML, Barreto MGM, Peralta RHS, Gargioni C, Gonçalves T, Igreja RP, et al. Immunoassays as an auxiliary tool for the serodiagnosis of Schistosoma mansoni infection in individuals with low intensity of egg elimination. Acta Trop. 2006;100(1):24-30.

3. Chitsulo L, Engels D, Montresor A, Savioli L. The global status of schistosomiasis and its control. Acta Trop. 2000;77(1):41-51.

4. World Health Organization (WHO). Schistosomiasis: number of people treated worldwide in 2013. Wkly Epidemiol Rec. 2015;90(5):25-32.

5. Cheever AW, Joffmann KF, Wynn TA. Kinetics of egg production and egg excretion by Schistosoma mansoni and S. japonicum in mice infected with a single pair of worms. Am J Trop Med Hyg. 1994;50(3):281-95.

6. Wynn TA, Thompson RW, Cheever AW, Mentink-Kane M. Immunopathogenesis of schistosomiasis. Immunol. 2004;201(1):156-67.

7. Baptista and Andrade. Angiogenesis and schistosomal granuloma formation. Mem Inst Oswaldo Cruz. 2005;100(2):183-5.

8. Wilson MS, Mentink-Kane MM, Pesce JT, Ramalingam TR, Thompson R, Wynn TA. Immunopathology of schistosomiasis. Immunol Cell Biol. 2007;85(2):148-54.

9. Chuah C, Jones MK, Mcmanus DP, Nawaratna SK, Burke ML, Owen $\mathrm{HC}$, et al. Characterising granuloma regression and liver recovery in a murine model of schistosomiasis japonica. Int $\mathrm{J}$ Parasitol. 2016;46(4):239-52.

10. Capron and Dessaint. Immunologic aspects of schistosomiasis. Annu Rev Med. 1992;43(1):209-18.

11. Kellermeyer RW, Warren KS, Waldmann TS, Cook JA, Jordon PRW, Kellermeyer K, et al. Concentration of serum immunoglobulins in St. Lucians with Schistosomiasis mansoni compared with matched uninfected St. Vincentians. J Infect Dis. 1973;127(5):557-62.

12. Rousseaux PR, Bazin H, Capron A. IgE in experimental schistosomiasis: I. Serum IgE levels after infection by Schistosoma mansoni in various strains of rats. Immunol. 1997;33(4):501-5.

13. Abbas AK, Murphy KM, Sher A. Functional diversity of helper T lymphocytes. Nature. 1996;383(6603):787-93.

14. Rumbley CA, Zekavat AS, Sugaya H, Perrin PJ, Ramadan MA, Phillips SM. The schistosome granuloma: characterization of lympochyte migration, activation, and cytokine production. J Immunol. 1998;161(8):4129-37.

15. Okano M, Satoskar AR, Nishizaki K, Abe M, Harn DA. Induction of $\mathrm{Th} 2$ responses and IgE is largely due to carbohydrates functioning as adjuvants on Schistosoma mansoni egg antigens. J Immunol. 1999;163(12):6712-7.

16. Mohrs M, Schramm G, Mohrs K, Wodrich M, Doenhoff MJ, Pearce EJ, et al. Cutting Edge: IPSE/alpha-1, a Glycoprotein from Schistosoma mansoni eggs, induces IgE-dependent, antigen-independent IL-4 production by murine basophils in vivo. J Immunol. 2007;178(10):6023-7.

17. Pearce EJ and Macdonald AS. The Immunobiology of schistosomiasis. Nat Rev Immunol. 2002;2(7):499-511. 
18. Schramm G, Gronow A, Knobloch J, Wippersteg V, Grevelding CG, Galle J, et al. IPSE/alpha-1: A major immunogenic component secreted from Schistosoma mansoni eggs. Mol. Biochem Parasitol. 2006;147(1):9-19.

19. Mosmann TR, Cherwinski H, Bond MW, Giedlin MA, Cofmann RL. Two types of murine helper $\mathrm{T}$ cell clones. I. Definition according to profiles of lymphonine activities and secreted proteins. J Immunol. 1986;136(7):2348-57.

20. Stadecker MJ and Hernandez HJ. The Immune response and immunopathology in infection with Schistosoma mansoni: a key role of major egg antigen Sm-p40. Parasite Immunol. 1998;20(5):217-21.

21. Butterworth AE, Bensted-Smith R, Capron A, Capron M, Dalton PR, Dunne DW, et al. Immunity in human schistosomiasis: Prevention by blocking antibodies of the expression of immunity in young children. Parasitol. 1987;94(2):281-300.

22. Teixeira CF, Neuhauss E, Ben R, Romanzini J, Graeff-Teixeira C. Detection of Schistosoma mansoni eggs in feces through their interaction with paramagnetic beads in a magnetic field. PLoS Negl Trop Dis. 2007;1(2):1-5.

23. Karl S, Gutiérrez L, Lucyk-Maurer R, Kerr R, Candido RRF, Toh SQ, et al. The iron distribution and magnetic properties of schistosome eggshells: implications for improved diagnostics. PLoS Neg1 Trop Dis. 2013;7(5):e2219.

24. Candido RRF, Favero V, Duke M, Karl S, Gutiérrez L, Woodward $\mathrm{RC}$, et al. The affinity of magnetic microspheres for Schistosoma eggs. Int J Parasitol. 2015;45(1):43-50.

25. Dalton JP, Day SR, Drew AC, Brindley PJ. A method for the isolation of schistosome eggs and miracidia free of contaminating host tissues. Parasitol. 1997;115(1): 29-32.

26. Boros DL, Warren KS. Delayed hypersensitivity-type granuloma formation and dermal reaction induced and elicited by a soluble factor isolated from Schistosoma mansoni eggs. J. Exp. Med. 1970;132:488-507.

27. Doenhoff MJ, Hassounah O, Murare H, Bain J, Lucas S. The schistosome egg granuloma: immunopathology in the cause of host protection or parasite survival? Trans R Soc Trop Med Hyg. 1986;80(4):503-14.

28. Karanja DMS, Colley DG, Nahlen BL, Ouma JH, Secor WE. Studies on schistosomiasis in western Kenya: I. Evidence for immune-facilitated excretion of schistosome eggs from patients with Schistosoma mansoni and human immunodeficiency virus coinfections. Am J Trop Med Hyg. 1997;56(5):515-21.

29. Deelder AM, Saad M, Din N, Kornelis D, Rene JM, Zeyl V. Immunologic characterization of two monoclonal antibodies reactive with repetitive carbohydrate epitopes of circulating Schistosoma mansoni egg antigen. J Trop Med. Hyg. 1994;50(4):487-98.
30. Die IV, Vliet SJY, Nyame AK, Cummings RD, Bank CMC, Appelmelk B. The dendritic cell-specific C-type lectin DC-SIGN is a receptor for Schistosoma mansoni egg antigens and recognizes the glycan antigen Lewis X. Glycobiology. 2003;13(6):471-8.

31. Neill PJG, Smith JH, Doughty BL, Kemp M. The ultrastructure of the Schistosoma mansoni egg. Am J Trop Med Hyg. 1988;39(1):52-65.

32. Pearce EJ. Priming of the immune response by schistosome eggs. Parasite Immunol. 2005;27(7-8):265-70.

33. Race GJ, Martin JH, Moore DY, Larsh JR. Scanning and transmission electronmicroscopy of Schistosoma mansoni eggs, cercarie and adults. Am J Trop Med Hyg. 1971;20(6):914-24.

34. Kariuki TM, Farah IO, Wilson RA, Coulson OS. Antibodies elicited by the secretions from schistosome cercarie and eggs are predominatly against glycan epitopes. Parasite Immunol. 2008;30(10):554-62.

35. Brandtzaeg P. History of oral tolerance and mucosal immunity. Ann NY Acad Soc. 1996;778(1):1-27.

36. Valencia A, Bastos ES, Conceição V, Campos SMN, Carvalho IP, Madi K, et al. Avaliação da interferência da tolerância oral na rejeição do transplante de coração alogênico avascular na orelha de camundongo. Braz J Cardiovasc Surg. 2006;21(1):75-84.

37. Linden, E. Identification of schistosomal eggs. Description of an immunological spot assay for hatch fluid antigen. J Immunol Methods. 1986;88(1):137-40.

38. Ashton PD, Harrop R, Shah B, Wilson RA. 2001. The schistosome egg: development and secretions. Parasitol. 2001;122(03):329-38.

39. Jang-Lee J, Curwen RS, Ashton PD, Tissot B, Mathieson W, Panico M, Dell A, et al. Glycomics analysis of Schistosoma mansoni egg and cercarial secretions. Mol Cell Proteomics. 2007;6(9):1485-99.

40. Dewalick S, Bexkens ML, van Balkom BWM, Wu YP, Smit CH, Hokke $\mathrm{CH}$, et al. The proteome of the insoluble Schistosoma mansoni eggshell skeleton. Int J Parasitol. 2011;41(5):523-32.

41. Wu YP, Lenting PJ, Tielens AGM, De Groot PG, Hellemond JJV. Differential platelet adhesion to distinct life-cycle stages of the parasitic helminth Schistosoma mansoni. J Thromb Haemost. 2007;5(10):2146-8.

42. Dewalick S, Hensbergen PJ, Bexkens ML, Grosserichter-Wagener C, Hokke CH, Deelder AM, et al. Binding of von Willebrand factor and plasma proteins to the eggshell of Schistosoma mansoni. Int J Parasitol. 2014;44(5):263-8.

43. File S. Interaction of schistosome eggs with vascular endothelium. J Parasitol. 1995;81:234-8.

44. Cass CL, Johnson JR, Califf LL, Xu T, Hernandez HJ, Stadecker MJ, et al. Proteomic analysis of Schistosoma mansoni egg secretions. Mol Biochem Parasitol. 2007;155(2):84-93. 